\title{
Pharmacokinetics of amphotericin B colloidal dispersion in liver
}

failure

\author{
Stefan Weiler, Rosa Bellmann-Weiler, Michael Joannidis and \\ Romuald Bellmann*
}

Address: Department of Internal Medicine, Medical University of Innsbruck, Austria

Email: Romuald Bellmann* - romuald.bellmann@i-med.ac.at

* Corresponding author

\author{
from 13th Scientific Symposium of the Austrian Pharmacological Society (APHAR). Joint Meeting with the Austrian Society of Toxicology (ASTOX) and the \\ Hungarian Society for Experimental and Clinical Pharmacology (MFT) \\ Vienna, Austria. 22-24 November 2007 \\ Published: 14 November 2007 \\ BMC Pharmacology 2007, 7(Suppl 2):A28 doi:10.1186/147I-2210-7-S2-A28
}

This abstract is available from: http://www.biomedcentral.com/I47I-22/0/7/S2/A28

(C) 2007 Weiler et al; licensee BioMed Central Ltd.

\section{Introduction}

Clinical studies on the elimination of amphotericin B $(\mathrm{AMB})$ lipid formulations in liver failure have been lacking so far. Therefore, the pharmacokinetics of AMB colloidal dispersion (ABCD) was assessed in critically ill patients with cholestatic liver failure.

\section{Patients and methods}

Time-concentration profiles were determined in critically ill patients with cholestatic liver failure and in critically ill patients with normal hepatic function requiring ABCD for invasive fungal infections. Lipid-associated and liberated AMB were separated by solid phase extraction and quantified by high performance liquid chromatography.

\section{Results}

Three patients with impaired and two patients with normal hepatic function (one patient on day 1, one patient on day 5 of therapy) were enrolled so far. After a single dose of $A B C D$, the $A M B$ half life was similar in patients with impaired and normal liver function. The AMB clearance was slower in liver failure $(0.15$ vs. $0.54 \mathrm{~L} / \mathrm{h} / \mathrm{kg}$ for total AMB, 0.22 vs. $0.55 \mathrm{~L} / \mathrm{h} / \mathrm{kg}$ for the liberated AMB fraction and 0.52 vs. $35.6 \mathrm{~L} / \mathrm{kg}$ for lipid-associated AMB) and the apparent volume of distribution was smaller (2.2 vs. $10.9 \mathrm{~L} / \mathrm{kg}$ for total $\mathrm{AMB}, 3.1 \mathrm{vs} .11 .2 \mathrm{~L} / \mathrm{kg}$ for liberated and 8.2 vs. $154.5 \mathrm{~L} / \mathrm{h} / \mathrm{kg}$ for lipid-associated AMB).

\section{Conclusion}

The elimination of ABCD appears to be delayed in cholestatic liver failure. More pharmacokinetic data are required to establish reliable dose recommendations for $\mathrm{ABCD}$ in patients with liver failure. 